\title{
O DIREITO DE BRINCAR NA INFÂNCIA: A ESCUTA ATENTA DAS CRIANÇAS NO COTIDIANO DA EDUCAÇÃO INFANTIL
}

\author{
THE RIGHT TO PLAY IN CHILDHOOD: THE DAILY CAREFUL LISTENING TO \\ CHILDREN IN ELEMENTARY SCHOOL
}

\author{
Aline Patricia Campos Tolentino de Lima \\ Doutoranda em Educação \\ Universidade de São Paulo - FFCLRP - USP \\ Ribeirão Preto, São Paulo - Brasil \\ alinepctolentino@hotmail.com \\ Evani Andreatta Amaral Camargo \\ Doutora em Educação \\ Universidade Estadual de Campinas - UNICAMP \\ Campinas, São Paulo - Brasil \\ evaniamaral@gmail.com
}

Resumo: Este texto faz parte da dissertação de mestrado de uma das autoras e aborda questões referentes ao brincar, partindo do princípio de que as crianças são sujeitos de direito. Neste sentido, a pesquisa apresenta o que as crianças têm a nos dizer sobre o brincar. Desenvolveu-se a partir da abordagem histórico-cultural, definindo-se a função da brincadeira no desenvolvimento infantil. O principal objetivo do trabalho foi proceder um levantamento sobre o que as crianças pensam sobre o brincar e quais são suas preferências. A metodologia utilizada foi a pesquisa qualitativa, com a realização de 21 entrevistas individuais, cinco rodas de conversa, registros fotográficos e um diário de campo sobre os momentos do brincar no cotidiano de uma instituição pública de educação infantil. Como resultado, foi possível ampliar os conceitos sobre a participação da criança na educação infantil, analisados a partir da opinião da criança e não apenas do adulto, propiciando ainda às pesquisadoras uma reflexão sobre os espaços e tempos destinados ao brincar nesse período escolar. Para este artigo serão apresentados episódios de duas rodas de conversa e um desenho de um dos sujeitos da pesquisa, enfatizando-se justamente a importância da escuta atenta das crianças e a da produção de desenhos, como os que foram realizados após a roda de conversa.

Palavras-chave: abordagem histórico-cultural; brincar; educação infantil.

\begin{abstract}
This paper is part of one of the authors' master's dissertation and addresses issues related to playing, assuming that children are subjects of rights. In this sense, the research presents what children have to tell us about playing. The research was developed from the cultural-historical approach, defining the role of play in child development. The work's main objective was to survey what children think about playing and what their preferences are. The methodology was that of qualitative research, with 21 individual interviews, five conversation circles, photographic records, and a field diary about the playing moments in the daily life of an elementary public school. As a result, it was possible to expand the concepts about the children's participation in early childhood education, based on children's opinion and not only the adult's, allowing the researchers to reflect on the spaces and times destined to play in this school period. This paper brings two episodes of conversation circles and a drawing by one of the subjects, emphasizing precisely the importance of careful listening to children and the production of drawings, such as those made after the conversation.
\end{abstract}

Keywords: cultural-historical approach; play; elementary school.

\section{Para citar - (ABNT NBR 6023:2018)}

LIMA, Aline Patricia Campos Tolentino de; CAMARGO, Evani Andreatta Amaral. O direito de brincar na infância: a escuta atenta das crianças no cotidiano da educação infantil. Eccos - Revista Científica, São Paulo, n. 59, p. 1-12, e13529, out./dez. 2021. Disponível em: https://doi.org/10.5585/eccos.n59.13529. 


\title{
1 Introdução
}

Este trabalho resultou da observação e reflexão da prática pedagógica de uma das autoras, que ao vivenciar o cotidiano na Educação Infantil percebeu a necessidade do brincar como atividade principal e com grande significação para o desenvolvimento pleno da criança.

Um dos objetivos principais desta pesquisa é dar voz às crianças, ancorados no paradigma da infância, que compreende as crianças como atores sociais e sujeitos de direitos, tendo como fundamento a pressuposição de que a participação infantil é uma questão social, política e científica.

\begin{abstract}
O brincar é essencialmente um direito de liberdade da criança que é reconhecida como pessoa com interesses, desejos e vontades muito singulares. Por isso, deve ser garantido, já que é sua realidade, bem como um elemento indispensável para que ela se desenvolva de forma plena e saudável. O brincar é a manifestação da liberdade da criança e é reconhecido como um direito porque somente ela pode exercê-lo por si contando com o apoio, respeito e o estímulo do adulto (FRANCO, 2008, p. 147).
\end{abstract}

A pesquisa está fundamentada na abordagem histórico-cultural. E a partir do tema principal deste estudo que é o brincar, foi possível, por meio do aprofundamento teórico dessa abordagem, analisar sob outra estratégia, como ocorre o processo de aprendizagem e desenvolvimento na infância. Por isso, a ênfase está em ouvir o que as crianças têm a dizer, pois são as maiores interessadas neste processo de desenvolvimento, em que devem ser consideradas como capazes e participativas de suas aprendizagens. E, desta maneira, a professora-pesquisadora buscou construir um espaço (intencional) para a participação da criança no cotidiano da escola de Educação Infantil.

A pesquisa buscou identificar quais são as preferências das crianças em relação às brincadeiras em uma instituição de Educação Infantil, de rede pública. Os objetivos específicos são: identificar, do ponto de vista das crianças, quais brincadeiras fazem parte do cotidiano da instituição; analisar a participação das crianças nas escolhas sobre o brincar; analisar a importância do brincar sob o ponto de vista infantil e, compreender, à luz da fundamentação teórica histórico-cultural, o papel das brincadeiras no desenvolvimento infantil.

Para este artigo, será feito um recorte da pesquisa de campo, apresentando episódios de duas rodas de conversas, com o princípio de reconhecer as crianças como atores sociais, sujeitos de direitos, trazendo a opinião infantil sobre o brincar. Também será apresentada uma das produções realizadas pelas crianças por meio do desenho, após a escolha da brincadeira preferida. 


\title{
2 Fundamentação teórica
}

Para Vigotski (2010), a criança não nasce em um mundo "natural”, ela nasce em um mundo humano, desde o nascimento entra em contato com objetos e fenômenos que foram criados pelas gerações anteriores e se apropria desta cultura por meio da interação social.

\begin{abstract}
Neste processo de interação social as reações naturais (condições biológicas) que respondem ao meio em resposta aos estímulos do meio, como percepção, a memória, as ações reflexas, as reações automáticas e as associações simples, entrelaçam-se aos processos culturalmente construídos por gerações anteriores e vão se transformando em modos de ação, de relação e de representação caracteristicamente humanos (FONTANA; CRUZ, 1997, p. 58).
\end{abstract}

Na perspectiva histórico-cultural, considera-se que uma das características da espécie humana é que o homem cria e constrói instrumentos, modifica o meio em que vive para agir sobre o seu ambiente, fazendo uma ação e transformando a natureza por meio dos aparelhamentos que cria (VIGOTSKI, 2007).

Esta relação entre o homem e o meio é sempre mediada por produtos culturais humanos, como instrumento e o signo, e pelo "outro" (VIGOTSKI, 2007). Podemos considerar instrumento tudo aquilo que serve como ferramenta para agir sobre o meio, e que lhe possibilite amplitude de suas ações biológicas, como, por exemplo: o homem não possui características biológicas em sua espécie para voar, mas ele criou o avião (instrumento) que o transporta nos ares e, assim, facilita de maneira mais rápida e eficaz seu ambiente de convívio social (OLIVEIRA, 1997).

Ainda segundo o autor acima, o signo, de acordo com a perspectiva histórico-cultural, seria o "instrumento psicológico", ou seja, tudo aquilo que é utilizado pelo homem para representar, evocar ou tornar presente o que está ausente. O instrumento está orientado externamente para modificar o ambiente, já o signo é orientado internamente, modifica o funcionamento psicológico do homem, ampliando as possibilidades de memória, raciocínio, planejamento, imaginação, entre outros.

A apropriação dos instrumentos e dos signos sempre acontece por meio da interação com o outro. Essa relação, desde o nascimento, é mediada pela linguagem; o adulto, por meio da língua de um grupo histórico-cultural, nomeia os objetos do mundo para o bebê, e aos poucos a criança também aprende a falar dando sentido às coisas que estão ao seu entorno.

A partir de suas relações com o outro, a criança reconstrói internamente as formas culturais de ação e pensamento, assim como as significações e os usos da palavra que foram com ela compartilhados. A esse processo interno de reconstrução de uma operação externa, Vigotski dá o nome de internalização (FONTANA; CRUZ, 1997, p. 60-61). 
Na perspectiva histórico-cultural, considerando o que foi dito, toda função psicológica se desenvolve em dois planos: inicialmente na relação entre os indivíduos e depois com o próprio indivíduo, o processo de desenvolvimento vai do social para depois acontecer de forma individual.

\section{Aspectos metodológicos}

A pesquisa se desenvolveu a partir da abordagem histórico-cultural, que tem como base a relação dialética, construída a partir do diálogo entre todos os envolvidos neste processo, resultando que pesquisador e pesquisado têm oportunidade para refletir, aprender e ressignificar-se no processo de pesquisa (FREITAS, 2003).

“A abordagem dialética, admitindo a influência da natureza sobre o homem, afirma que o homem, por sua vez, age sobre a natureza e cria, através das mudanças nelas provocadas, novas condições naturais para sua existência" (VIGOTSKI, 2007, p. 62). A relação dialética que se constitui na pesquisa de campo qualitativa, torna possível a interpretação do pesquisador por meio da ação reflexiva de todo o contexto histórico dos sujeitos envolvidos, com a consciência de que o pesquisador também tem um contexto histórico-cultural que influencia no processo dialético da pesquisa.

Na construção dos dados da pesquisa qualitativa é considerada a questão da importância da fidelidade aos sujeitos e pesquisador (MINAYO, 2012), sendo que toda compreensão é parcial e inacabada, tanto a do sujeito da pesquisa, que tem um entendimento contingente e incompleto de sua vida e de seu mundo, como a do pesquisador, que também tem uma compreensão e interpretação limitadas.

Ao realizar uma pesquisa qualitativa deve-se considerar o sujeito investigado como um ser histórico que sofre influências do ambiente em que vive, bem como o pesquisador, porém não se pode deixar que opiniões e conceitos próprios interfiram na pesquisa, para não comprometer o resultado da mesma. Para isso, os pesquisadores apoiam-se, de um lado, em uma perspectiva teórica e, de outro, no que autores contemporâneos discutem a respeito da mesma temática.

Para esse trabalho, a pesquisa de campo foi realizada pela pesquisadora, enquanto professora com sua turma de vinte e um alunos, na faixa etária de quatro a cinco anos, que frequentavam a Educação Infantil em uma rede pública municipal, localizada no interior de São Paulo. 
Para o levantamento dos dados, ocorrido entre os meses de maio e agosto de 2018, primeiramente foi encaminhado o projeto de pesquisa a um Comitê de Ética em Pesquisa com Seres Humanos, que foi aprovado sob o número do parecer 2.735.555. Após isso, obteve-se a autorização da gestora da instituição e dos responsáveis pelos alunos. Com as crianças que foram autorizadas a participar, foram explicados os objetivos da pesquisa e suas contribuições, questionando-as se gostariam de participar, e elas aceitaram o convite.

A pesquisa teve o intuito de investigar a visão do brincar do ponto de vista infantil. Para tanto, foi necessário construir com as crianças, um espaço que lhes permitiu manifestar suas ideias de modo organizado, respeitando as características e particularidades do mundo da infância e possibilitando discussões, reflexões e encaminhamentos. Desta maneira, buscou-se a escuta atenta das crianças e, dentre as temáticas discutidas, as brincadeiras preferidas, quais brincadeiras conheciam e como eram, e ainda quais brincadeiras aconteciam em casa e na escola.

Como já explicitado, uma das etapas da pesquisa de campo foi a realização de cinco rodas de conversa com a turma de crianças, cuja discussão principal se deu sobre qual era a brincadeira favorita da turma. Na última roda de conversa, foi realizada uma votação, por meio de desenhos, sobre a brincadeira preferida. Após a pesquisadora elencar os votos, a brincadeira eleita pela turma foi vivenciada por todos.

\section{Resultados e discussões}

A discussão, em um momento coletivo, era uma prática pedagógica já realizada pela pesquisadora com os alunos enquanto professora atuante na Educação Infantil, como recurso pedagógico de escuta atenta das crianças, denominada "Roda de Conversa". A autora Freire (1983) descreve a roda de conversa em sua prática pedagógica na Educação Infantil, como um momento importante em que as crianças têm a possibilidade de um conhecimento maior entre si, bem como da professora com relação a elas e vice-versa, além das narrativas de suas vivências e experiências realizadas individual ou coletivamente.

A roda funciona como um dispositivo democrático, um meio pelo qual as crianças e os adultos podem ir compreendendo as questões que geram situações de mal-estar, de desconforto e de conflito no grupo, bem como é um espaço para emitir suas ideias, seus sentimentos e seus desejos, além do que lhes causa prazer. Desse modo, podem discutir formas de resolver questões (ANGELO, 2011). 
A roda de conversa serve como uma prática dialógica (MOTTA, 2011), permitindo à criança o direito à voz e é justamente nessa relação com o outro, mediada pela linguagem que o ser humano vai se constituindo. Escutar o que as crianças têm a dizer sobre o brincar é possibilitar concebê-las como sujeitos ativos, que participam de forma criativa e crítica do seu processo de aprendizagem e desenvolvimento.

Para Vigotski (2010), a fala é um dos signos mais importantes na mediação do desenvolvimento e a linguagem exerce uma função organizadora para que a criança possa compreender o mundo por meio das palavras. As interações entre adulto - criança e criança criança, que aconteceram nas rodas de conversa, contribuíram para que os alunos participassem de forma ativa, expressando sua opinião sobre o brincar, e, a pesquisadora pôde desenvolver o papel de mediadora, que por meio das palavras fez com que as crianças elaborassem e reelaborassem suas ideias, de acordo com a cultura e o contexto, sobre brincadeiras que vivenciavam em seu cotidiano.

Neste sentido, as rodas de conversa aconteceram para promover discussões em grupo sobre as brincadeiras preferidas das crianças, e possibilitaram o surgimento de detalhes e acordos entre os sujeitos envolvidos na pesquisa.

A realização de rodas de conversa além do objetivo primário de permitir a expressão das crianças sobre as brincadeiras preferidas, também foi dar ênfase em ouvir o que elas têm a dizer por meio de rodas e depois, decidirem ou realizar assembleias, assim como acontece na abordagem educativa italiana (EDWARDS; GANDINI; FORMAN, 2016).

No referido trabalho, foram realizadas cinco rodas de conversas para discutir as brincadeiras preferidas, sendo a última para decidir, por meio de uma votação, qual era a preferida da turma em questão, e finalmente brincarem juntos.

Na quarta roda de conversa, ocorrida no dia 08 de maio de 2018, com vinte crianças presentes, o tema foi o conceito de votação, em que cada um dos participantes iria escolher sua brincadeira preferida e, após isso, desenhá-la em um cartão e colocar em uma urna. A brincadeira mais votada pela turma seria a vencedora. Após a eleição, todos iriam brincar.

Nessa roda, o aluno Bruno, um dos sujeitos da pesquisa, fez uma associação entre a votação da brincadeira e a eleição presidencial, que iria ocorrer no segundo semestre do ano da pesquisa. O menino explicitou que seu pai iria votar em um presidente, como podemos verificar a seguir: 
EPISÓDIO - “4a. Roda de conversa sobre qual era a brincadeira preferida” (08/05/2018)

(1) Pesquisadora: Esta roda de conversa de hoje, é como se fosse uma assembleia, quando várias pessoas se reúnem para votar e tomar uma decisão do que será feito. No nosso caso estamos decidindo qual é a brincadeira preferida da turma.

(2) Bruno: Há já sei, igual quando meu pai vota no presidente.

(3) Pesquisadora: Sim, é parecido com a votação para presidente, vocês gostaram dessa ideia?

(4) Crianças: Sim!

Assim, destacamos a importância da intencionalidade do adulto para a introdução de um conceito. Nessa situação, a pesquisadora, ao propor uma votação, ao explicar o que seria uma assembleia, fez com que a criança se apropriasse do conceito, relacionando a situação de sala de aula ao momento de votação no país, que estava circulando em outros espaços sociais. Lembrando-se que no ano de 2018 ocorreram em nosso país, eleições para vários cargos políticos. No período do levantamento e construção dos dados já estavam ocorrendo propagandas eleitorais, o que fez com que Bruno relacionasse as informações.

É importante ainda destacar como um fator cultural que está ligado diretamente às narrativas das crianças que participaram da roda, contribuiu inclusive para a formação de conceitos. Como se pode observar, Bruno relacionou o fato de votar em sua brincadeira preferida ao de seu pai votar em um presidente. Fez associações por meio da mediação do adulto, que propôs que cada criança votasse em sua brincadeira preferida; ele, além de fazer uma associação de ideias reelaborou um conceito, em outras palavras, apropriou-se desse conceito da cultura.

De acordo com Prestes e Santana (2018), para a abordagem histórico-cultural, a história do desenvolvimento humano remete, obrigatoriamente, a seu caráter cultural. Quando se olha para o desenvolvimento da criança por meio do brincar, também se deve olhar para a cultura em que a criança está inserida, como um processo de sua humanização.

$\mathrm{Na}$ roda de conversa da aula anterior, foi proposto que as crianças votassem em sua brincadeira preferida, por meio de desenhos que foram postos em uma urna, como referido no episódio anterior. Nesse dia, coletivamente, após a apuração da votação, marcada na lousa pela pesquisadora, vivenciar-se-ia a brincadeira mais votada pelas crianças. 
EPISÓDIO - "5a. Roda de conversa: escolha da brincadeira preferida" (11/05/2018)

(1) Pesquisadora: Bom dia, pessoal, hoje em nossa roda de conversa vamos abrir a urna e contar as brincadeiras que vocês desenharam no cartão e colocaram aqui. Vou anotando na lousa e vocês vão me ajudando a contar, certo?

(2) Pesquisadora: Primeira brincadeira, pé de feijão! (Anotou na lousa)

(3) Pesquisadora: Brincar no parque! Carrinho! Pula na cama! Pega-pega! Cavalo! Jogar bola! Bola!

(4) Gustavo: Esse é o meu!

(5) Pesquisadora: Olha a brincadeira com bola já tem dois pontos. Olha só mais um ponto para bola. Continuando, Ônibus! Boneca! Casinha! Boneca! Bola! Dinossauro! Casinha! Escorregador! Parque! Pega-Pega! Bola! (Tirando os cartões da urna mostrando e anotando na lousa cada brincadeira).

(6) Pesquisadora: Pessoal, qual foi a brincadeira mais votada?

(7) Crianças: Bola!

(8) Pesquisadora: Quantos votos na brincadeira com bola?

(9) Luiza: Cinco.

(10) Pesquisadora: Isso mesmo, cinco crianças votaram na brincadeira com bola, e como combinamos agora a gente vai no pátio brincar com bola!

(11) Raul: Eeee...eu gosto de brincar com bola.

A pesquisadora fez uma fila e todos foram ao pátio externo para brincar com bola. Nas figuras apareceram jogo de futebol e jogo de basquete. Foi um momento muito divertido que as crianças adoraram e do qual participaram.

Sobre a vivência da brincadeira preferida da turma, houve a brincadeira de jogar futebol e basquete. Além da importância da intencionalidade do adulto de propor experiências às crianças para que elas se apropriem da cultura que a cerca, deve-se chamar-se atenção para os espaços/ambiente que possibilitam diferentes experiências.

\footnotetext{
Quanto mais a criança viu, ouviu e vivenciou, mais ela sabe e assimilou; quanto maior a quantidade de elementos da realidade de que ela dispõe em sua experiência - sendo as demais circunstâncias as mesmas - significativas e produtivas será a atividade de sua imaginação (VIGOTSKI, 2010, p. 23).
}

A imaginação, que é a base criadora de toda atividade humana, só é possível devido ao fato de o cérebro humano não ser apenas um órgão que retém o que foi apreendido e reproduzido, mas sim, que tem a capacidade de combinar e reelaborar, através da criação; sendo que a imaginação surge devido às experiências vivenciadas anteriormente.

O brincar está relacionado diretamente com alguns fatores culturais, como se pode ver, à influência da mídia, dos brinquedos comercializados e à do contexto familiar das crianças envolvidas. Pela escuta nas rodas de conversa, descobriu-se como o brincar vai se constituindo no cotidiano da criança em diferentes ambientes, escolar e familiar. 


\begin{abstract}
A compreensão dos significados das coisas do mundo, das pessoas com quem nos relacionamos e de nós mesmos constrói-se com base em situações partilhadas e vivenciadas com outros sujeitos, nos afetos e conhecimentos, no confronto de pontos de vistas e na descoberta e criação de novos sentidos. Somente assim é possível conhecer o ser humano completo. Em Vygotsky, a formação das funções psicológicas estritamente humanas ocorre na vivência do sujeito no meio, que não é só físico, mas carregado de significados, pleno de ideologia, de história e de cultura (PRESTES; SANTANA, 2018, p. 143).
\end{abstract}

É discutido na abordagem teórica (VIGOTSKI, 2010), que o desenvolvimento humano ocorre por meio da mediação social que se refere à participação do outro nesse desenvolvimento, desde o início da sua vida, por meio das interações e intervenções desse outro, possibilitando a apropriação dos instrumentos e signos da cultura em que se está inserido. Neste sentido, pode-se observar que o processo de formação e desenvolvimento da criança está sempre ligado às relações sociais que vão se constituindo ao longo de sua vida.

Nesse trabalho, também foi apresentada uma análise sobre a produção de um dos desenhos que aluna Sara (4 anos) realizou para representar a sua brincadeira preferida, após as discussões da roda de conversa. De acordo com a perspectiva histórico-cultural, a criança desenha o que está na memória; quando uma criança libera sua memória por meio do desenho, ela faz à maneira da fala, contando histórias, narrando (LACERDA, 1995).

A seguir, encontra-se a produção da criança. O desenho foi o registro da brincadeira que ela escolheu como preferida para a votação da sala. A pesquisadora perguntou qual o nome da brincadeira antes de ela colocar na urna e escreveu embaixo do desenho.

Figura 1 - Desenho realizado por Sara (4 anos)

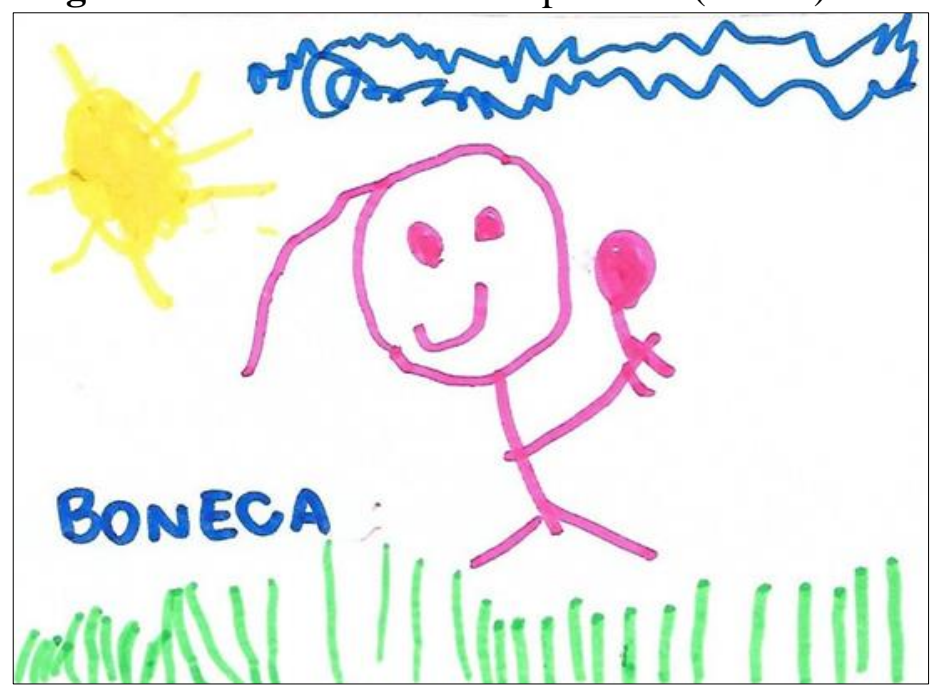

Fonte: LIMA (2019, p. 107).

O desenho apresenta uma figura humana com esquema corporal com detalhes sobre o que a criança conhece sobre a brincadeira de boneca. De acordo com Vigotski (2009), o desenho 
é um tipo predominante de criação na infância, em que a criança representa o que ela sabe sobre o objeto e não o que ela vê. No caso da figura acima, Sara representou sua brincadeira preferida. Observa-se uma menina segurando uma boneca do que se conclui que assim como o brincar, o desenhar é uma experiência que leva ao desenvolvimento das possibilidades criadoras da criança.

De acordo com a perspectiva histórico-cultural, o desenho pode ser visto como um signo empregado pelo homem e constituído a partir das interações sociais (SILVA, 1998).

A fala organiza o desenho e quando a criança nomeia o que vai desenhar está sendo orientada pela palavra. E assim, de acordo com Vigotski (2009), a criança é levada a construir funções psicológicas superiores em suas relações com o outro, com o uso dos signos, como no ato de desenhar e representar o que sabe sobre aquilo.

\section{Considerações finais}

Pode-se afirmar, de acordo com os resultados dessa pesquisa, baseada na abordagem histórico-cultural, que as vivências do brincar das crianças estão relacionadas ao seu contexto cultural e tais informações surgem em suas falas, como foi possível observar nos episódios das rodas de conversa aqui apresentados. Vale argumentar que a brincadeira, a partir dessa linha teórica, é uma forma de expressão e apropriação do mundo das relações que a criança tem, como foi possível ver na fala de Bruno ao associar a votação da brincadeira preferida com o fato de seu pai votar em um presidente.

Também foi ressaltada, neste estudo, a importância da escuta atenta das crianças no cotidiano da Educação Infantil, na construção coletiva de um espaço intencional para prover com ênfase a participação das crianças em seu processo de desenvolvimento, e que as mesmas devem ser consideradas capazes e participativas.

E por meio da brincadeira e desenho, foi possível analisar a atividade criadora da criança, uma ação especificamente humana. Para a perspectiva histórico-cultural, a plasticidade cerebral é a capacidade que o cérebro humano tem de não apenas armazenar e reproduzir mecanicamente a experiência vivida, mas de recriar por meio de experiências, algo novo para satisfazer uma necessidade, seja ela própria ou de âmbito social, e aqui identificamos a importância da brincadeira e do desenho.

A conclusão a que se chega é que no desenvolvimento infantil, a brincadeira, por meio da situação imaginária, contribui de forma efetiva para a apropriação das funções psíquicas 
superiores da criança, juntamente com a produção criadora dos desenhos que é essencial para seu desenvolvimento.

\section{Referências}

ANGELO, A. O espaço-tempo da fala na Educação Infantil: a roda de conversa como dispositivo pedagógico. In: ROCHA, E. A. C.; KRAMER, S. (orgs.) Educação Infantil: enfoques em diálogos. Campinas: Papirus, p. 53-65, 2011.

EDWARDS, C.; GANDINI, L.; FORMAN, G. As cem linguagens da criança: a abordagem de Reggio Emilia na Educação da primeira infância. Porto Alegre: Penso, 2016.

FONTANA, R.; CRUZ, N. Psicologia e trabalho pedagógico. São Paulo: Atual, 1997.

FRANCO, R. R. A fundamentação jurídica do direito de brincar. 2008. 252f. Dissertação (Mestrado em Educação). Universidade Estadual de Londrina, Londrina, 2008. Disponível em: https://www.ppedu.uel.br/en/more/dissertations-theses/dissertations/category/172008?download=354:2008-franco-raquel-rodrigues. Acesso em: 03 abr. 2019.

FREIRE, M. A paixão de conhecer o mundo. Rio de Janeiro: Paz e Terra, 1983.

FREITAS, M. T. A. A perspectiva sócio-histórica: uma visão humana da construção do conhecimento. In: FREITAS, M. T. A.; SOUZA, S. J.; KRAMER S. (Org.). Ciências Humanas e Pesquisa: Leituras de Mikhail Bakhtin. São Paulo: Cortez Editora, 2003, p. 26-38.

LACERDA, C. B. F. Oralidade, desenho e escrita: o processo de construção do conhecimento. São Paulo: Cabral Editora. 1995.

LIMA, A. P. C. T. O brincar na educação infantil sob a ótica da criança. 2019. 127 f. Dissertação (Mestrado) - Centro Universitário Moura Lacerda, Ribeirão Preto, 2019. Disponível em: http://dissertacoes.mestrado.mouralacerda.edu.br/buscas_trabalhos-portalmouralacerda.php?busca_trabalho $=\&$ busca_ano $=2019 \&$ busca_semestre $=$. Acesso em: 15 nov. 2021.

MINAYO, M. C. S. Análise qualitativa: teoria, passos e fidedignidade. Cienc. Saúde Coletiva, v.17, n.3, p. 621-626, 2012. Disponível em:

https://www.scielo.br/j/csc/a/39YW8sMQhNzG5NmpGBtNMFf/?lang=pt\&format=pdf. Acesso em: 20 set. 2019.

MOTTA, F. Salada de crianças: a roda de conversa como prática dialógica. In: ROCHA, E. A. C.; KRAMER, S. (orgs.) Educação Infantil: enfoques em diálogos. Campinas: Papirus, v. 2, p. 67-84, 2011.

OLIVEIRA, M. K. Vygotsky: aprendizado e desenvolvimento um processo sócio-histórico. São Paulo: Scipione, 1997.

PRESTES, Z.; SANTANA, C. C. G. A teoria histórico-cultural como uma possibilidade para o estudo do desenvolvimento da criança. In: SANTOS, M. W.; TOMAZZETTI, C. M.; 
LIMA, Aline Patricia Campos Tolentino de; CAMARGO, Evani Andreatta Amaral. O direito de brincar na infância: a escuta atenta das crianças no cotidiano da educação infantil

MELLO, S. A. (orgs.) Eu ainda sou criança: educação infantil e resistência. São Carlos: EdUFSCar, 2018. p. 137-145.

SILVA, M. C. S. Condições sociais da constituição do desenho infantil. Psicol. USP. 1998, v.9, n.2, p. 205-220. Disponível em: http://dx.doi.org/10.1590/S0103-65641998000200008. Acesso em: 06 abr. 2019.

VIGOTSKI, L. S. A formação social da mente: o desenvolvimento dos processos psicológicos superiores. São Paulo: Martins Fontes, 2007.

VIGOTSKI, L. S. Imaginação e criação na infância. São Paulo: Ática, 2009.

VIGOTSKI, L. S. Psicologia pedagógica. São Paulo: WMF Martins Fontes, 2010. 